\title{
O ESPETÁCULO QUE EDUCA O CORPO: CLUBES ATLÉTICOS NA CIDADE DE NITERÓI DOS ANOS 1880
}

Victor Andrade Melo ${ }^{1}$

\section{RESUMO}

Este artigo objetiva discutir duas iniciativas esportivas ao redor das quais se pode observar discursos de educação do corpo, articulando a dinâmica do espetáculo e posicionamentos ligados à educação física - as experiências do Clube Atlético Brasileiro e do Clube Olímpico Guanabarense, agremiações dedicadas centralmente às corridas a pé fundadas na Niterói dos anos 1880. Para alcance do objetivo, como fontes foram utilizados relatos de memorialistas, bem como revistas e jornais publicados na capital fluminense e no Rio de Janeiro no período em tela. Na interpretação, teve-se em conta os princípios da eficácia, propriedade e identidade na esteira do que sugere Vigarello (2003), Isso é, aquilo que se relaciona, respectivamente, à educação do físico, do espírito e para inserção em coletivos.

Palavras-chave: história da educação, história do esporte, história do corpo.

${ }^{1}$ Universidade Federal do Rio de Janeiro (UFRJ), Rio de Janeiro/RJ, Brasil. 


\title{
EL ESPECTÁCULO QUE EDUCA EL CUERPO: CLUBES ATLÉTICOS EN LA CIUDAD DE NITERÓI DE LOS AÑOS 1880
}

\section{RESUMEN}

Este articulo tiene por objetivo discutir dos iniciativas deportivas alrededor de las cuales se pude observar discursos de educación del cuerpo, articulando la dinámica del espectáculo y posicionamientos ligados a la educación física - las experiencias del Clube Atlético Brasileiro y del Clube Olímpico Guanabarense, dedicados centralmente a las carreras a pie que se fundaron en Niterói de los años 1880. Para alcanzar el objetivo, como fuentes se utilizaron relatos de memorialistas, así como revistas y periódicos publicados en la capital fluminense y en Río de Janeiro en el período. En la interpretación, hemos tenido en cuenta los principios de eficacia, propiedad e identidad desde lo que sugiere Vigarello (2003). Eso es, respectivamente, lo que se relaciona con la educación del físico, del espíritu y la inserción en colectivos.

Palabras clave: história de la educación, história del deporte, história del cuerpo.

\section{THE SPECTACLE EDUCATING THE BODY: ATHLETIC CLUBS IN THE CITY OF NITERÓI IN THE 1880's}

\begin{abstract}
This article has for purpose to discuss two sporting initiatives in which intentions of body education were observed, articulating the dynamics of the spectacle and certain discourses related to physical education - the experiences of the Clube Atlético Brasileiro and the Clube Olímpico Guanabarense, associations dedicated centrally to the races, founded in the Niterói of the 1880 s. In order to reach the objective, as sources were used memorialists and newspapers published in Niterói and Rio de Janeiro in the period. In the interpretation, we have considered the principles of efficacy, property and identity as Vigarello (2003) suggests. This is, respectively, what is related to the education of the physical, the spirit and for insertion into collectives.
\end{abstract}

Keywords: education history, sport history, body history.

\section{LE SPECTACLE QUI EDUQUE LE CORPS: CLUBS ATHLÉTIQUE DANS LA VILLE DE NITERÓI DES ANNÉES 1880}

\section{RÉSUMÉ}

Cette étude a pour but de discuter deux initiatives sportives dans lesquelles des intentions d'éducation du corps ont été observées, en articulant la dynamique du spectacle et certains discours liés à l'éducation physique - les expériences du Clube Atlético Brasileiro et du Clube Olímpico Guanabarense, deux associations fondées à Niteroi dans les années 1880 et principalement dédiées aux courses à pied. Pour atteindre cet objectif, nous avons utilisé des magazines et journaux publiés dans la ville de Niteroi et celle de Rio de Janeiro au cours de la 
période considérée. Dans cette analyse, nous avons pris en compte les principes de l'efficacité, de la propriété et de l'identité suivant Vigarello (2003). C'est à dire, respectivement, ce qui est lié à l'éducation du physique, de l'esprit et à l'insertion dans des collectifs.

Mots-clés: histoire de l'éducation, histoire du sport, histoire du corps. 


\section{INTRODUÇÃO}

Em 1573, na banda oriental da Baía de Guanabara, se estabeleceu a Aldeia de São Lourenço, uma decorrência das preocupações com a defesa da América portuguesa, desencadeadas pela invasão dos franceses liderados por Villegagnon, no mesmo cenário em que se fundara o Rio de Janeiro, em 1565. A região demorou a melhor se estruturar (AZEVEDO, 1997, p. 20). Somente em 1819, deixou de ser conhecida como Bandas D’Além, passando a ser denominada Vila Real da Praia Grande. No ano seguinte, um plano de urbanização da zona central começou a transformar a localidade (CAMPOS, 2004).

Novo e determinante impulso para seu desenvolvimento se deu a partir de 1834, quando, em função da criação do Município Neutro da Corte, Niterói denominação somente estabelecida em 1835 - tornou-se capital da Província do Rio de Janeiro. Um novo plano de urbanização para a região de Icaraí e Ingá (1840) (CAMPOS, 2004), a instalação de fábricas (com destaque para o Estaleiro Mauá) (HONORATO; BEAUCLAIR, 1997) e a chegada de novos habitantes, inclusive lideranças políticas (FERREIRA, 1997), marcaram um primeiro ciclo de modernização da cidade².

Não se pode dizer que esse impulso modernizador reverteu por completo a dinâmica provinciana de Niterói. Ainda assim, não devemos desprezar a importância das iniciativas que tinham em conta sintonizar a cidade com as ideias de civilização e progresso, com o ideário e imaginário da modernidade.

Essas ações também objetivavam legitimar sua condição de capital fluminense, algo dificultado pela forte influência e costumeira intervenção da Corte nos mais diferentes âmbitos (AZEVEDO, 1997; FERREIRA, 1997). Como sugere Peixoto, "Rio e Niterói são cidades espelhadas, filhas da Guanabara que as gerou juntas para destinos interligados. O inimigo é a metrópole que pode

\footnotetext{
${ }^{2}$ Esse ciclo de modernização foi encerrado na década de 1890, quando Niterói tanto perdeu parte de seu território, com a autonomia de São Gonçalo, quanto, em função dos conflitos da Revolta da Armada, por alguns anos deixou de ser a capital do Estado, transferida para Petrópolis entre 1894 e 1903 (FORTE, 1973).
} 
fagocitar Niterói, reduzindo-a a um subúrbio" (1997, p. 201).

No decorrer do século XIX, portanto, assim como ocorreu em outras cidades, em Niterói sentiu-se a necessidade de educar o povo para os novos procedimentos públicos, para que aprendesse a se comportar no cenário social que se delineava, bem como adquirisse hábitos considerados saudáveis e higiênicos. Desencadearam-se, em meios escolares e não escolares, discursos e intervenções de controle e disciplinarização, muitos deles tendo os usos do corpo como alvo primordial.

Entre as ocorrências que nos permitem perceber tanto o maior desenvolvimento e progresso de Niterói quanto sua intensa relação com a Corte, podemos situar a estruturação de um mercado de entretenimentos, entre os quais se delinearam iniciativas esportivas, experiências antecedidas pela oferta de diversões nas quais se destacavam as performances corporais (tais como circos, touradas e patinação), indicadores de que se gestava uma nova sensibilidade pública da qual o esporte seria tributário. Vale considerar que Friedman e Bustad (2017) sugerem tratar-se de uma intensa relação a que historicamente se estabeleceu entre processos de urbanização e a sistematização do campo esportivo3.

Este artigo tem por objetivo discutir duas iniciativas esportivas ao redor das quais se pode observar discursos de educação do corpo, articulando a dinâmica do espetáculo e posicionamentos ligados à educação física - as experiências do Clube Atlético Brasileiro e do Clube Olímpico Guanabarense, agremiações dedicadas centralmente às corridas a pé fundadas na Niterói dos anos 1880 .

Para alcance do objetivo, como fontes foram utilizados relatos de memorialistas, bem como revistas e jornais publicados na capital fluminense e no Rio de Janeiro no período em tela. Tendo em conta a característica do material

\footnotetext{
3 Para um debate sobre o esporte no cenário internacional, ver Vigarello e Holt (2008). Sobre a prática em cidades brasileiras, ver Melo (2010a).
} 
consultado, seguimos as sugestões de Luca (2005), considerando que os posicionamentos de cronistas devem ser prospectados a partir do seu perfil e do periódico no qual eram veiculados.

Há que se destacar que as iniciativas de educação do corpo são entendidas como "processo amplo de adequação a certos costumes, algo que passa pelo aprendizado de técnicas corporais [...], bem como de comportamentos julgados adequados (modos de tocar, de se portar, de se vestir, de comer, entre outros)" (MELO; SANTOS, 2018, p. 1033). Tendo em conta investigar os diversos constrangimentos que cercam a experiência corporal, vale prospectar "as técnicas, pedagogias e instrumentos" (SOARES, 2001, p. 111) utilizadas para tal.

Distintos são os parâmetros e estratégias de intervenção, algo que deve ser compreendido num continuum que vai das questões contidas na própria ideia de cultura às encaminhadas por instituições que atuam de forma mais específica no processo de educação4. Entre essas podemos falar da escola, mas também daquelas ligadas às práticas corporais institucionalizadas (como clubes esportivos e ginásticos, bem como sociedades dançantes), âmbitos que, inclusive, se cruzam nos debates entabulados ao redor da educação física, entendida como proposta ampla de educação, não só uma disciplina escolar.

Neste estudo, investigamos uma dessa iniciativas de intervenção, aquelas entabuladas em função das atividades de duas agremiações esportivas. $\mathrm{Na}$ interpretação, teve-se em conta o que Vigarello (2003) chama de facetas da experiência corporal. $\mathrm{O}$ autor chama de "princípio da eficácia" aquilo que é relacionado à "educação do físico", o que tange à força e destreza, às valências físicas. De "princípio da propriedade", denomina o tocante à sensibilidade e comportamentos, a "educação do espírito". Já o "princípio da identidade" tem a ver com a inserção dos indivíduos em coletivos maiores. Para cada uma dessas dimensões, deve-se ter em conta que "as referências dadas à forma, às eficácias e funcionamentos do corpo, mudam no decorrer do tempo. Suas representações se

\footnotetext{
4 Para uma discussão sobre a importância das intervenções educacionais corporais, ver Soares (2001) e Sant'anna (2000).
} 
deslocam de tal maneira que, algumas vezes, veem-se completamente transformadas" (VIGARELLO, 2003, p. 21).

Vejamos o que se pode perceber no cenário específico da cidade de Niterói naquela década de 1880.

\section{PRIMEIRAS MANIFESTAÇÕES PÚBLICAS DE UMA CULTURA CORPORAL}

Nos anos 1830, começou a se estruturar um mercado de entretenimentos em Niterói. Nessa década, tornou-se notável a programação de um teatro instalado na região central da cidade, estabelecimento dinamizado pelos Chiarini, oriundos de uma tradicional família circense italiana.

Em 1835, os Chiarini começaram a se apresentar na Corte, especialmente no Teatro Constitucional Fluminense (antigo Real Teatro São João) (MELO; PERES, 2014). Os espetáculos mesclavam números de equilíbrio, força, malabarismo, dança, canto, palhaço. Em 1836, pela primeira vez a Companhia se exibiu em Niterói, no Teatro Niteroiense (JORNAL DO COMÉRCIO, 1835).

Em 1837, José Chiarini construiu dois pequenos teatros, um no Rio de Janeiro, no Largo da Ajuda (atual Cinelândia), e outro em Niterói, no Largo Municipal (nos dias de hoje conhecido como Jardim de São João), onde se encontrava a Igreja Matriz e o governo instalara um chafariz para minimizar os problemas de abastecimento de água, bem como mandaria construir a Casa da Câmara e a Cadeia (MARTINS, 2009).

O teatro dos Chiarini, portanto, foi instalado na região mais urbanizada, onde habitava a maior parte da população, inclusive as elites, e se situavam importantes edificações, na qual acontecia com mais intensidade a vida cotidiana. Além disso, encontrava-se perto da estação das barcas - cujo serviço regular iniciara-se em 1835, o que facilitava a chegada dos que vinham da Corte. Houve, a propósito, a preocupação de oferecer horários especiais para atender esse 
público.

Essa relação com a Corte vai marcar a trajetória de Niterói no decorrer do século XIX e décadas iniciais do XX. As lideranças intelectuais e políticas reivindicavam maior autonomia, bem como propugnavam a necessidade de forjar uma identidade própria, que não fosse confundida com a da poderosa capital que se encontrava do outro lado da Baía de Guanabara. Argumentamos que as práticas corporais foram também mobilizadas para tal fim, na esteira do que Vigarello (2003) define como "princípio da identidade”.

Ao inaugurar o estabelecimento, Chiarini assumiu que as instalações ainda não eram confortáveis, mas já tomou cuidados comuns aos empreendimentos de diversão da época, tais como reservar locais exclusivos para as mulheres e ofertar ingressos a preços acessíveis (JORNAL DO COMÉRCIO, 1837a). Logo o teatro foi reformado e a programação incrementada, inclusive com participação de artistas estrangeiros. A casa passou a ser anunciada como Círculo Olímpico e Teatro Ginástico da Cidade de Niterói.

O êxito parece ter sido notável. Chegou a haver um caso curioso. Em dia de outubro de 1837, o público compareceu em peso mesmo não tendo sido anunciado espetáculo devido ao mau tempo. O artista se apressou "em suplicar a bem merecida desculpa, ao mesmo tempo que agradece, com sinceridade e respeito, mais essa prova da pública proteção” (JORNAL DO COMÉRCIO, 1837b, p. 3).

Chamamos a atenção para esse estabelecimento na esteira do que sugerem Melo e Peres (2014): os números circenses anteciparam e durante décadas influenciaram o desenvolvimento do gosto pelas exibições corporais. Há que se ter em conta que, a partir de 1837, o termo ginástica já era mais claramente utilizado na definição dos espetáculos de Niterói. José Chiarini chegou a ser apresentado como "professor e diretor da Companhia Gymnastica” (JORNAL DO COMÉRCIO, 1837c, p. 2).

Uma nova performance pública era apresentada e tornava-se 
paulatinamente apreciada pela população. Dialogando com Vigarello (2003), podemos sugerir que, na ocasião, tratou-se, ainda, menos de um processo de "educação do físico" e mais de uma iniciativa que aponta para uma "educação do espírito”. De toda forma, esta será importante para criar condições para aquela.

Em 1838, a companhia de Chiarini se afastou do teatro do Rio de Janeiro e investiu ainda mais no estabelecimento de Niterói. Ao que parece, continuou a lograr grande sucesso, tornando-se um dos principais espaços de entretenimento da cidade que passava por mudanças a fim de conformar sua condição de capital da Província. Era uma expressão da nova dinâmica pública, ainda modesta, mas já em curso de transformação.

Até 1840, quando se encerrou sua trajetória5, o teatro acolheu espetáculos dos mais diferentes perfis. Críticas intensas somente surgiram quando o espaço começou a ser usado para a realização de touradas. A arena já acolhia cerca de 3.000 pessoas quando passou a promovê-las, à moda portuguesa, sem morte dos animais que tomavam parte das lides sempre embolados (com armações de couro e metal nos cornos para reduzir os riscos de toureiros).

A adequação da prática era posta em xeque. De um lado, os mais vinculados a noções de progresso e civilização as consideravam ultrapassadas. De outro, assustava aos mais conservadores o comportamento turbulento do público. Ao redor das corridas de touros se manifestavam as tensões entre diferentes projetos de cidade (MELO, 2015a). Ao ser debatido esse "princípio da propriedade" (VIGARELLO, 2003), delineava-se o que deveria ser aceito e estimulado no que tange aos usos do corpo, aos comportamentos aceitáveis na cena pública.

Essa é mais uma referência de manifestação que precedeu a construção de uma cultura esportiva em Niterói. Outros circos se instalaram na cidade no

\footnotetext{
5 Pelos jornais, percebemos que Chiarini leiloou todo o material da arena (DIÁRIO DO RIO DE JANEIRO, 1840, p. 4) e viajou para a região sul do país, provavelmente para por lá também apresentar seus espetáculos.
} 
decorrer dos anos 1840-1860, boa parte deles com exibições ginásticas. Novo perfil de estabelecimento, no qual também se oferecia a possibilidade de praticar algum exercício físico, somente se estruturou nos anos 1870. Um deles foi o Café Recreio de Icaraí, cujo funcionamento se inspirava nas fábricas de cerveja e outros centros de diversão do Rio de Janeiro, integrando venda de bebidas e comida com a oferta de espetáculos e atividades diversificadas (MELO; KARLS, 2018).

Em 1875, um certo Thomaz Reeve solicitou autorização para instalar, em Icaraí, "um estabelecimento de hospedaria para os frequentadores dos banhos de mar, Tivoly para recreio do povo, teatro, jardins, jogos lícitos, exercícios ginásticos, de armas, de tiro ao alvo, e outros entretenimentos" (ANAIS DA ASSEMBLEIA LEGISLATIVA..., 1875, p. 169). Ao fim, dois anos depois, quem protagonizou a iniciativa e se tornou proprietário foi Joaquim Manuel Rodrigues.

Localizado na Rua do Souza (atual Gavião Peixoto), tornou-se um apreciado centro de divertimentos, oferecendo, além de hospedagem, bebida e comida, apresentações musicais, atrações exóticas, cancha de jogo da bola, bem como exibições e possibilidades da prática da ginástica.

Em mais de uma ocasião, o estabelecimento convidou os aficionados pela prática, com especial interesse por um grupo específico: “Atenção, classe caixeiral, alerta! Reuni-vos hoje à tarde no Café Recreio de Icaraí a fim de assistir aos trabalhos de ginástica e música" (GAZETA DE NOTíCIAS, 26 ago. 1877, p. 4). Melo e Peres (2014) já identificaram que, no Rio de Janeiro, havia forte envolvimento de jovens comerciantes com a modalidade. Trata-se de um indício de que setores urbanos de estrato médio estiveram entre os principais interessados nos exercícios físicos. Perceba-se como avançavam as preocupações com o que Vigarello (2003) denominou "princípio da eficácia". Uma nova proposta de "educação do espírito" apresentava possibilidades de "educação do físico".

Há que se ter em conta que Icaraí crescia rapidamente e tornava-se conhecido por ser um lugar aprazível, moderno, bom para descanso e 
entretenimentos (CAMPOS, 2004). Além disso, facilitava a chegada ao bairro a melhoria dos meios de transporte urbanos, o que ajudava a atrair, inclusive, gente da Corte ${ }^{6}$.

A propósito, outro estabelecimento vindo do Rio de Janeiro, também encarado como sinal dos avanços civilizacionais da cidade (MELO, 2017), se integrou à dinâmica de entretenimentos de Niterói. Em 1878, no palacete que pertenceu a Pinto Peixoto e fora Câmara e Assembleia, situado na Rua do Visconde do Uruguai, esquina com Rua do Imperador (atual Rua Marechal Deodoro), foi inaugurado o Novo Skating-Rink, dinamizado pela mesma equipe e proprietário do rinque de patinação da capital nacional, o suíço/alemão Hermann Wilhelm Glette.

Para além da oferta da prática da patinação - chegou a se disponibilizar aulas para os que desejavam aprender ou aperfeiçoar suas habilidades -, o estabelecimento foi concebido também como um espaço de apresentações e divertimentos diversos. Houve até mesmo uma companhia própria dedicada a exibições ginásticas à moda dos espetáculos circenses.

Como na Corte, a patinação era apresentada como uma fashionable diversão. O cronista que assinava como Fábio adendou outra reflexão, relacionando a modalidade à saúde: "O nosso físico precisa de atividade afim de se fortificar e se pôr a serviço da alma com rapidez. Nada melhor para isso do que a patinação. Eis o caso de se dizer que reúne-se o útil ao agradável” ( $O$ FLUMINENSE, 1878 , p. 3)7. Não se tratava, portanto, de somente estimular a assistência, mas também propugnar a prática de exercícios com um objetivo maior do que somente o entretenimento. Delineava-se ainda mais a ideia de uma "educação do físico" (aquilo que Vigarello chamou de "princípio da eficácia".

A despeito dos discursos celebratórios, a princípio, o público não se

\footnotetext{
${ }^{6}$ Em 1871, inaugurou-se uma linha de bonde com tração animal que fazia o percurso estação das barcas-Icaraí.

7 Editado em Niterói, nos seus momentos iniciais, O Fluminense circulou também na Corte. Mesmo primando por uma linha editorial política conservadora, esteve engajado na modernização e avanço civilizacional da capital fluminense.
} 
animou, passando a comparecer em maior número quando tornou-se gratuita a entrada e reduziu-se o valor do aluguel de patins. Além disso, assim como houve na Corte (MELO, 2017), em Niterói se percebe certa restrição à modalidade em função das dificuldades de praticá-la. Na capital fluminense, também se criticou o comportamento dos frequentadores, por alguns considerados turbulentos em demasia.

Chocavam-se as novas propostas de "educação do espírito" e de "educação do físico" com comportamentos típicos não só de práticas mais antigas, como também de um substrato da própria gestação de uma cultura de massas. $\mathrm{O}$ público, na visão de alguns cronistas, precisava ser educado a assistir e se exercitar de acordo com os novos parâmetros civilizatórios.

Alguém que assinou como "O Escabriado" sugeriu ter sido "grande o número de famílias que tem deixado de frequentar o estabelecimento" por perceber que não se tratava de "um divertimento digno", mas sim "uma completa pândega" (O FLUMINENSE, 1879a, p. 4). Outro que se identificou como "Diogenes" o identificava como "um precipício para os homens que se prezam e para as famílias honestas (O FLUMINENSE, 1879b, p. 4). O Skating-Rink reagiu a tais acusações por meio de sua propaganda: "entrada grátis às famílias e pessoas decentemente vestidas, sendo vedada a entrada às que se julgar inconvenientes ao estabelecimento" (O FLUMINENSE, 1880, p. 4).

Tratava-se de resistências à nova possibilidade de exibição e movimentação corporal? Talvez menos isso e mais questões relativas à classe social dos frequentadores. Na verdade, um conflito se instituiu. Em função das entradas gratuitas, muitos iam ao Skating-Rink somente para assistir e se divertir com os tombos, não pagando para patinar, o que trazia problemas para o proprietário, do ponto de vista simbólico e material.

Ampliar o número e diversidade de apresentações foi a saída encontrada para atrair mais público pagante. Essa solução, todavia, alterou a dinâmica do estabelecimento - deixava de ser eminentemente dedicado às atividades físicas para se tornar mais um teatro. Se antes era um espaço da ginástica per si, a 
patinação sendo considerada uma forma de cuidar do corpo, transformara-se num local de exibições de certos exercícios que, àquela altura, já estavam a ser combatidos pelos médicos por supostamente desvirtuarem os objetivos louváveis da prática (MELO; PERES, 2014). As críticas ao Skating-Rink aumentaram em função desse perfil "dúbio". Em 1880, deixou de existir e transformou-se no Teatro Fênix Niteroiense.

Tanto se adotarmos um conceito mais estrito de esporte (MELO, 2010b) quanto se percebermos os posicionamentos dos envolvidos, essas experiências não podem ser consideradas stricto sensu como esportivas, mas são importantes indícios de uma vida pública mais ativa e de uma maior sensibilidade para com as práticas corporais. São decorrências do processo de urbanização e circulação de ideias de civilização e progresso do qual fazia parte a estruturação de um mercado ao redor dos entretenimentos. Apresentavam novas possibilidades e restrições de usos do corpo.

Isso se acentuou quando se estruturou o campo esportivo. Em Niterói, esse processo somente se tornou mais claro na década de 1880. Algumas iniciativas pioneiras, todavia, foram entabuladas nas décadas anteriores.

\section{PRIMEIROS PASSOS DO ESPORTE}

Alguns memorialistas informam que uma suposta disputa entre duas canoas - Cabocla e Lambe-Água, conduzidas por Alecrim e José Ferro, teria ocorrido em $1846^{8}$. Efetivamente, não foram encontradas referências nos jornais sobre tal desafio, o que não significa dizer que não tenha acontecido.

A propósito, não é difícil que outras disputas semelhantes tenham sido realizadas. O mais importante é termos em conta a representação que adquiriu

\footnotetext{
${ }^{8}$ Essa informação se espalhou, com maior ou menor debate, por sítios na internet e produções de historiadores amadores e profissionais. Entre os memorialistas, ver Mendonça (1909), Edmundo, (1956) e Dunlop (1960).
} 
no decorrer do tempo. O desafio teria partido da Enseada de Jurujuba (Niterói) e chegado na Praia de Santa Luzia (Rio de Janeiro), trajeto bem simbólico das ligações entre as cidades.

De toda forma, não se pode considerar esses desafios, stricto sensu, como primeiras manifestações do esporte náutico. Antes, eram uma expressão da maior ocupação das praias para fins que não medicinais, mas sim de diversão, algo também relacionado à nova dinâmica pública e à conformação de hábitos modernos (MELO, 2014).

Outro fato comumente citado pelos memorialistas é a fundação, em 1851, de um grupo náutico, o Mareantes, em uma chácara pertencente a João de Mattos, localizada no Valonguinho. Uma vez mais, não foi possível obter outras evidências para além das citações em sítios, relatos de memorialistas e estudos acadêmicos, nenhum deles referenciando fontes primárias, todos aparentemente dialogando entre si.

A crer que, de fato, esse grupo existiu, há que se destacar o seu formato mais institucionalizado - uma agremiação que intentava promover regatas - e sua localização mais próxima do Centro de Niterói, onde se encontrava o mais importante núcleo urbano da cidade. Vale ter em conta que, no Rio de Janeiro, também em 1851, foi fundada a Sociedade Recreio Marítimo, clube que promoveu, na Enseada de Botafogo (portanto, Baía de Guanabara), uma pioneira regata bem estruturada, dando início ao longo processo de consolidação do remo na Corte (MELO, 2015b; MELO, 2015c).

No Rio de Janeiro, nas décadas de 1850 e 1860, sem grande regularidade foram promovidas muitas regatas. Essas iniciativas por vezes envolviam gente de Niterói. O cronista do folhetim de A Pátria ${ }^{9}$ (1856) sugeriu que, em 1856, um grupo formado por brasileiros e estrangeiros da Corte pretendia organizar páreos

\footnotetext{
9 Editado por Carlos Bernardino de Moura, era um periódico marcado por sua oposição a grupos conservadores. Durante alguns anos, chegou a se chamar Eco da Nação e Revolução Pacifica. Vereador, liberal, Moura se notabilizou como liderança abolicionista e republicana. Para mais informações, ver Carvalho (2007).
} 
de remo entre a Armação (Ponta d'Areia) e o Gragoatá.

No ano seguinte, há outra evidência de provas planejadas para serem realizadas na enseada de Icaraí. Em 1858, houve páreos de oito escaleres, com largada no cais da Cadeia (na Armação) e chegada na Ponte do Imperador (na altura da Rua São João). Essas ocasiões deixaram poucos registros, não nos permitindo identificar seus graus de organização e mobilização.

Em 1862, realizaram-se alguns páreos que parecem ter tido maior repercussão (CORREIO MERCANTIL, 1862a). Não havia ainda agremiações estruturadas, mas percebe-se que os responsáveis possuíam certo conhecimento da organização do esporte náutico. De fato, entre esses havia alguns que participavam da promoção de provas no Rio de Janeiro, entre os quais Francisco Leão Cohn, filho de comerciante francês, militar de destacada carreira, funcionário da Alfândega, um dos diretores da Sociedade Regata (MELO, 2015b; MELO, 2015c).

Os promotores eram personagens importantes de Niterói, como João Maria Wandenkolk, Barão de Araguari e Almirante de prestígio. Outros militares de alta patente da Armada também estiveram envolvidos, tal como Jesuíno Lamego Costa, o Barão de Laguna. Deve-se destacar ainda a ativa participação do advogado e juiz José Secundino Gomensoro, bem como de Antônio Luiz da Cunha Manso Sayão, um dos fundadores do Imperial Instituto Médico Fluminense. Tratava-se de gente ligada a uma burguesia urbana em formação, integrada por comerciantes, profissionais liberais e funcionários públicos, entre os quais membros das forças armadas.

Os responsáveis pela promoção do evento tinham em conta tanto contribuir para que Niterói passasse a melhor reconhecer esses "avanços" civilizacionais, um intuito claro de educar a população para desfrutar uma atividade que apontava para outro uso do corpo da cena urbana, quanto demonstrar a capacidade organizacional da capital fluminense. Vemos a articulação entre o que Vigarello (2003) define como "princípio da propriedade" e "princípio da identidade". 
Prevista para 29 de junho - possivelmente em conjunto com a inauguração dos serviços da Companhia de Barcas Ferry, ocasião que mobilizou a cidade, contando, inclusive, com a presença do Imperador, a regata, contudo, foi transferida para 6 de julho. Tratou-se de evento bem organizado, com seis páreos para diferentes tipos de embarcação (canoas e escaleres de distintas quantidades de remo), sempre no formato de duas guarnições se enfrentando. A raia ia da Armação até a ponte das barcas. Os remadores eram membros das famílias dos organizadores, gente de Niterói e do Rio de Janeiro já envolvida com a modalidade.

Para o responsável pela coluna "Chronica de São Domingos", do Correio Mercantil $^{10}$ - na qual se narrava os principais acontecimentos da capital fluminense -, a regata "esteve concorridíssima" (1862b, p. 2). O público assistiu às provas do litoral, de barcas ancoradas no mar (com a advertência de que não podiam atrapalhar a competição) e da ponte da Fábrica de Refinação e Destilação de açúcar (somente para convidados). Novas possibilidades de exposição corporal desfilavam nas raias, observadas por gente que também começava a cultivar costumes mais distendidos e que, portanto, precisavam ser educados (perceba-se como aqui trabalhamos com a ideia de "princípio da propriedade" de Vigarello, 2003).

Na ocasião, mesmo que passando por mudanças, Niterói era ainda uma cidade modesta do ponto de vista da infraestrutura e da população. Não surpreende que a regatas tenha contado com a presença de público da Corte, da mesma forma que gente da capital fluminense constantemente assistia aos páreos promovidos no Rio de Janeiro. Isso não era encarado apenas como importante para viabilizar o evento, mas também como sinal de reconhecimento do valor da capital fluminense ("princípio da identidade", nas considerações de Vigarello, 2003).

É importante destacar o simbolismo do evento. Numa ocasião em que se

${ }^{10}$ Publicado de 1848 a 1868, tinha um perfil político liberal e engajado, ao contrário do Jornal do Comércio, sempre marcado por posições mais moderadas (RIBEIRO, 2005). 
aperfeiçoava o serviço de barcas (a ligação com o Rio de Janeiro), Niterói celebrava movimentos de modernização com uma competição esportiva que contava com importantes personagens da cidade. A boa repercussão na Corte foi interpretada como sinal de que a cidade se consolidava como capital da Província.

No encerramento, realizado nas dependências do Teatro Santa Tereza ${ }^{11}$, a premiação foi feita "pelas mãos de lindas senhoras e um sarau veio terminar a festa" (JORNAL DO COMÉRCIO, 1862, p. 4). Foi uma celebração urbana bem aos moldes civilizatórios já usuais na Corte. Novos comportamentos públicos eram apresentados e exigidos. Os frequentadores precisavam aprender os limites desses novos usos do corpo.

A despeito dos bons resultados, não foi fácil promover outros eventos náuticos em Niterói. O cronista do Correio Mercantil (1862c, p. 2) chegou a comentar: "Entretanto, já se fala de uma nova regata; temos certeza e quase afiançados de que só terá lugar desta data a três anos”. Para ele, na cidade era usual que a empolgação inicial fosse se arrefecendo no decorrer do tempo, fazendo malograr as iniciativas. De fato, percebe-se que o processo de "educação do espírito" (VIGARELLO, 2003) ainda estava dando os primeiros passos, lideranças e população em geral ainda se apropriando das novas possibilidades que se delineavam.

Havia, todavia, outras dimensões que ajudam a explicar a interrupção das iniciativas esportivas. A proximidade com o Rio de Janeiro atraia para lá olhares e investimentos. A criação do Clube de Regatas, na Corte, na mesma época, foi um importante passo para a definitiva consolidação do remo na Baía de Guanabara (MELO, 2015c). Além disso, já se identificou, na segunda metade dos anos 1860, uma redução das atividades públicas em função de certas epidemias/endemias ${ }^{12}$, de dificuldades econômicas e dos impactos da Guerra do

\footnotetext{
${ }^{11}$ Principal teatro da cidade, era ainda administrado por João Caetano. No mesmo lugar, hoje se encontra o Teatro Municipal de Niterói.

${ }^{12}$ Em Niterói, entre outros, houve problemas com a febre amarela, cólera, tuberculose, disenteria, varíola (PIMENTA; BARBOSA; KODAMA, 2005).
} 
Paraguai (MELO, 2017).

Deve-se também ter em conta que um aspecto central na conformação do campo esportivo é a estruturação de agremiações, o que, em Niterói, somente nos anos 1880 começou a ocorrer ${ }^{13}$. Vamos abordar as experiências de dois clubes atléticos ${ }^{14}$.

\section{PELA EDUCAÇÃO FÍSICA DO POVO}

Em maio de 1881, no salão do Congresso Literário Guarany, uma das associações mais importantes de Niterói à época, reuniu-se um grupo de interessados em fundar um running club (O FLUMINENSE, 1881), uma agremiação dedicada às corridas a pé e jogos atléticos, antecedentes do atletismo, práticas que se tornaram uma febre na Corte nos anos 1870-1880 (MELO, 2015d; MELO; PERES, 2016a).

Para julho do mesmo ano, foi marcada a inauguração do Clube Atlético Brasileiro, um programa de sete páreos a serem realizados no Largo do Barreto. As corridas tiveram lugar na chácara do comendador Domingos Moutinho (O GLOBO, 1881), um dos proprietários da Companhia Carris Urbano e de outras empresas de transporte atuantes na Corte e em outras Províncias.

O Largo do Barreto, nos dias de hoje Praça Enéias de Castro, a essa altura se encontrava à beira mar: "A orla era bordada de coqueiros, daí o nome da praia, transmitido ao porto que existia no local e à rua que dele seguia pela margem norte da mesma praça” (SOARES, 1993, p. 259). O logradouro tornou-se e durante décadas permaneceu sendo um centro de entretenimento ${ }^{15}$.

\footnotetext{
${ }^{13}$ Houve uma exceção de curta duração, o Prado Icaraiense, fundado e extinto em 1877.

14 Nos anos 1880, também foram criados clubes de remo e turfe, tema de outro estudo.

${ }_{15} \mathrm{Na}$ altura, o Barreto ainda era ponteado de propriedades rurais. Crescera ao redor do porto que servia como escoadouro de produção agrícola que vinha da região de São Gonçalo, especialmente de Neves. Na década de 1890, contudo, concebido pelo governador Francisco Portela como um núcleo industrial (SOARES, 1993), começaria a ser ocupado por fábricas, o que mudaria suas características de ocupação. A Praia e o Porto dos Coqueiros desapareceram,
} 
Protagonistas na criação e manutenção da agremiação foram os Couto especialmente Alberto, Frederico Tutte (também fundador do Clube Olímpico Guanabarense), Henrique Tutte e Julieta Tutte, netos de Pedro do Couto, proprietário de terras no Barreto desde o início do século XIX. Tratava-se de uma família que tinha ascendência britânica (SOARES, 1993), o que pode ajudar a entender sua relação com o esporte.

Importantes personagens de Niterói desempenharam a função de corredores e dirigentes do Clube Atlético Brasileiro, entre os quais o advogado José Francisco de Sá Junior, o comerciante Miguel da Cunha Ipyranga Guaranys, Dionísio Feijó de Castro (que também foi ativo no Clube Olímpico Guanabarense) e os membros da família do notório médico Guilherme March, morador do Barreto - o comerciante W. March, o tipógrafo Jorge March, o estudante de medicina Adolfo March e o futuro professor Edmundo March (SOARES, 1993). Como se pode perceber, como era usual nas outras iniciativas esportivas, os principais envolvidos eram membros de uma burguesia urbana ligada ao comércio e profissões liberais.

Os eventos da agremiação, promovidos regularmente entre os anos de 1881 e 1888, eram marcados por empolgação e presença de grande público. Eram sempre animados por um grupo musical de Niterói. Os páreos mesclavam corridas, saltos e, eventualmente, outras modalidades, como cabo de guerra. A princípio, somente sócios podiam concorrer, a posteriori, qualquer um, desde que pagando uma taxa de inscrição. Havia provas para adultos e crianças, homens e mulheres ${ }^{16}$. A participação feminina era encarada como um sinal de avanço civilizacional, expressão de seu novo protagonismo social, marca dos novos tempos ${ }^{17}$.

na década de 1960, com os aterros realizados para a construção da Avenida do Contorno.

${ }^{16}$ Entre as mais costumeiras competidoras, encontravam-se a já citada Julieta do Couto, Julieta Guanabarino (filha do notório maestro Oscar Guanabarino, regente da Filarmônica Niteroiense), Zizinha de Figueiredo (provavelmente membro da família dos advogados Aleixo Marinho de Figueiredo e Joaquim Antunes de Figueiredo Júnior), Amanda Peña (da família de Eric Peña, cônsul do Uruguai e comerciante).

${ }_{17}$ Sobre a maior presença e participação de mulheres nas competições esportivas das décadas finais do século XIX, ver Melo (2007). 
Os eventos do Clube Atlético eram apresentados como "festas de educação física". Genesdio ${ }^{18}$, no folhetim Ecos Guanabarenses, era um dos que exaltava essa ideia:

\begin{abstract}
É com esses exercícios que se prepara uma geração de fortes e animosos cidadãos; é com esses clubes que se arrancam dezenas de jovens da ociosidade e do vício [...]. Um abraço fraternal, pois, a esses moços que sabem atrair-se útil e honestamente, fortalecendo o corpo para revigorar o espírito. Parabéns a Niterói, parabéns ao Clube Atlético do Barreto (O FLUMINENSE, 1882a, p. 1).
\end{abstract}

Perceba-se a explícita mobilização da ideia de educação física - não a disciplina escolar, mas sim um processo amplo de educação na esteira do que Vigarello (2003) definiu como "princípio da eficácia". Se antes, era mais usual nas experiências corporais a manifestação de preocupações com a "educação do espírito", ao redor das atividades dos clubes atléticos, os discursos passaram a mais intensamente as articular com as necessidades de uma educação ligada à força, à destreza, ao desenvolvimento muscular.

Esse mesmo cronista, em outra ocasião, saudou "esses moços honestos que por esse útil e agradável passatempo vão corrigindo os nossos costumes, despertando os sentimentos mais nobres do homem" (O FLUMINENSE, 1882b, p. 2). Claramente, se procedia uma vinculação a um novo conjunto de compreensões sobre a dinâmica social, relacionadas ao processo de adesão a noções de progresso e modernidade, destacando-se as preocupações com a saúde e higiene, em muitas ocasiões associadas com as atividades físicas - o esporte e a ginástica (MELO; PERES, 2014).

Na verdade, a ideia de utile dulce sempre marcou o forjar do campo esportivo. Esgrimia-se o argumento de que não se tratava de qualquer diversão, mas sim algo que poderia ser útil aos cidadãos e à nação (MELO, 2014). A

18 Genesdio era o pseudônimo do escritor Alfredo Azamor, personagem importante da intelectualidade niteroiense. Abolicionista e liberal, se notabilizou pelos desejos de contribuir para o progresso de Niterói (SOARES, 1993). 
diferença, no decorrer do tempo, é que seria mais enfatizado o exercício físico em si, sempre articulado com a possibilidade de assistir performances corporais exibidas em espetáculos públicos.

Também Luiz Fernandes ${ }^{19}$ se derramou em elogios aos eventos do Clube Atlético Brasileiro. Para ele, além de sua importância para a educação física, contribuíam para "fazer progredir uma cidade como Niterói, rebelde a divertimentos" (O FLUMINENSE, 1882c, p. 2). Com grande entusiasmo narrava as disputas, combatia restrições à modalidade e convocava a todos - homens $\mathrm{e}$ mulheres - a tomarem parte nas iniciativas da agremiação, para ele um sinal de avanço civilizacional. A preocupação desse cronista era com o progresso da capital fluminense, algo que relacionava com a necessidade de reduzir a dependência com a Corte. $\mathrm{O}$ esporte era encarado como importante contributo para tal fim. Trata-se do que Vigarello (2003) denominou de "princípio da identidade".

Vejamos que, a despeito desses discursos, em muitas ocasiões houve apostas nos páreos. Não se registrou, contudo, ao contrário das corridas de cavalos, qualquer tumulto aparente. Os corredores somente ganhavam brindes e presentes, jamais qualquer remuneração. Era mesmo um divertimento que aspirava ser civilizado e sinal do progresso de Niterói. Uma propaganda da necessidade da educação física do povo. Pode-se entender claramente esse ponto de vista a partir da articulação dos três princípios propostos por Vigarello (2003): eficácia, propriedade, identidade.

Em 1887 e 1888, percebem-se sinais de mudanças no Clube Atlético Brazileiro, tentativas de viabilizar financeiramente a agremiação que encontrava dificuldades para manter-se em funcionamento. No decorrer desses anos, alguns eventos foram ainda promovidos. Aparentemente, todavia, não mais corridas foram realizadas em 1889 .

\footnotetext{
${ }^{19}$ Foi um dos mais importantes cronistas de Niterói do século XIX. Membro de uma importante família da Província, foi funcionário público, literato e notável jornalista (SOARES, 1993). Era liberal e abolicionista; um homem sintonizado com a ideia de progresso.
} 
Para Luiz Fernandes, a agremiação acabou por desencadear na cidade um deleite esportivo específico, ligado mais à compleição física. Nas suas palavras, "o gosto pelos exercícios atléticos vai em progresso entre nós e até já está dominando o espírito da meninada" (O FLUMINENSE, 1883a, p. 1). Esse cronista, sempre tão cioso de propor a modernização da cidade, encarava tal postura como uma necessidade no sentido de configurar mais claramente uma identidade e uma autonomia de Niterói no que tange a seu relacionamento com a Corte. Físico, espírito e identidade se articulavam em seu discurso.

De fato, logo surgiram outras iniciativas semelhantes, como a criação do Clube Atlético Juvenil no Liceu Popular (um dos mais importantes da capital fluminense, atual Liceu Nilo Peçanha) ${ }^{20}$ e, notadamente, de outra sociedade que foi assumindo o protagonismo da modalidade e do esporte em Niterói, o Clube Olímpico Guanabarense.

Há que se destacar que, na Corte e em Niterói, já há alguns anos havia certa circulação da palavra "olímpico", antes mesmo de terem sido recriados os Jogos (Atenas, 1896). Tanto em escritos de médicos quanto em iniciativas do âmbito do entretenimento (como em certos circos), o termo era utilizado para expressar atleticismo e vigorosidade (MELO; PERES, 2016b). O Clube Olímpico Guanabarense se ajustava plenamente a essas ideias.

A iniciativa parecia melhor estruturada do que a do Clube Atlético Brasileiro. Localizado na Rua de Santa Rosa, com raia de boa extensão (300 metros), ofereceu, desde o início, uma arquibancada preparada para acolher bom público (900 pessoas). Estava, portanto, situado próximo da região de Icaraí que, como vimos, crescia e se notabilizava como local de entretenimentos. Se a agremiação do Barreto se encontrava no subúrbio, na fronteira entre a cidade e o campo, a sede do Clube Olímpico se instalara num lugar identificado como moderno e mais acessível.

\footnotetext{
${ }^{20}$ A iniciativa de alunos do Liceu Popular foi muito elogiada por alguns cronistas da cidade, como por Genesdio (O FLUMINENSE, 1885). Esse clube atlético funcionou entre 1886 e 1888, promovendo corridas na Rua do Visconde do Itaboraí, bem próximo ao Largo da Memória (atual Praça do Rink).
} 
$\mathrm{Na}$ inauguração, realizada em setembro de 1883, programaram-se 14 páreos. Além das usuais corridas diversas para homens, mulheres, adultos e crianças, introduziu-se uma prova de velocípedes, antecedentes da bicicleta. Foi um dos primeiros clubes do Brasil a oferecer tais disputas (SCHETINO, 2008), mais um sinal de que a diretoria desejava se sintonizar com a ideia de progresso e avanço civilizacional. Ainda mais do que o Clube Atlético e do que as iniciativas anteriores, pretendia-se contribuir para a "educação do espírito" da cidade.

Ao mesmo tempo, isso se articulava com iniciativas de "educação do físico". A sede ficava aberta para os associados que desejassem treinar. Entre estes e dirigentes se encontrava gente importante de Niterói, inclusive alguns que já estavam envolvidos com o Clube Atlético Brasileiro (como parte da família Couto). Podemos citar o médico e liderança política Carlos Maximiano de Azevedo e Silva; o conhecido comerciante, político (chegou a ser presidente da câmara) e membro de uma das principais famílias da cidade João Francisco Fróes da Cruz; o comerciante e político Manuel dos Santos Moreira.

A imprensa niteroiense e da Corte encheu de elogios o clube. Considerou as instalações confortáveis e adequadas à prática da modalidade e ao recebimento do público, que, a propósito, usualmente compareceu em peso, inclusive notáveis personagens da cidade, até mesmo políticos de renome, como o presidente da Província, Bernardo Avelino Gavião Peixoto. Descortina-se aqui uma das facetas sugeridas por Vigarello (2003): as ações do Olímpico também foram mobilizadas no sentido de conformar uma identidade para a capital fluminense. Vislumbravase que poderiam contribuir para que o niteroiense desenvolvesse mais intensamente mecanismos de identificação com sua cidade.

Ao comentar a atividade inaugural, Luiz Fernandes comemorou o fato de estar em funcionamento mais um clube atlético na cidade, algo que, a seu ver, só poderia trazer benefícios para a sociedade niteroiense. Curiosamente, sugeria que os frequentadores evitassem luxo nas vestimentas, conclamando que as agremiações atuassem para repudiar o "ar aristocrático" (O FLUMINENSE, 
1883b, p. 2) 21. As corridas deveriam ser, no seu entender, a expressão de um novo tempo, não se confundindo com antigos entretenimentos. Perceba-se as mudanças no que tange às compreensões acerca de novos comportamentos públicos valorizados.

Não por acaso, portanto, Luiz Fernandes sugeriu que o excesso de bailes - uma das diversões mais usuais do momento - poderia causar danos à saúde, inferindo que "o mesmo porém, não acontece às corridas que, sendo um divertimento campestre e diurno, fazem os seus frequentadores gozar um ar mais puro que o das suas casas, sem prejuízo do sono" (O FLUMINENSE, 1883c, p. 2). No seu olhar, mesmo os eventos dançantes, outrora tão elogiados, deveriam ser superados pelas atividades dos clubes atléticos, mais adequadas para forjar o progresso que desejava para a capital fluminense. Os discursos tentavam posicionar os cidadãos acercas dos novos usos do corpo, da adequação (ou não) de antigas possibilidades, conclamando a "avanços" na forma de compreender essas alternativas. "Princípio da eficácia": regulava-se o exercício físico na sua articulação com um novo "espírito", supostamente mais apropriado aos novos tempos.

No final de seu primeiro ano de funcionamento, observa-se uma mudança no perfil da agremiação ${ }^{22}$ : tanto passou a atender melhor os associados, gente da elite de Niterói, quanto acolheu maior público em geral ao adotar para suas atividades uma dinâmica mais espetacular. Reformaram-se as instalações. Aperfeiçoou-se o funcionamento do serviço de comidas e bebidas. Bondes extras da Companhia Carris facilitavam a chegada dos frequentadores.

A dinâmica espetacular tinha em conta garantir meios para viabilizar a existência do clube, mas também potencializar o alcance de sua visibilidade, o que era celebrado por algumas lideranças intelectuais por ser potenciais

${ }^{21}$ Esse tema voltou diversas vezes às crônicas, tratado como sinal de provincianismo.

22 O Clube Olímpico transformou-se em sociedade anônima, adquirindo ações os que se interessassem em ser sócios. Tratou-se de uma reorganização da agremiação para adequá-la à lei n. 3130 de 4 de novembro de 1882. 
contribuições para consolidar determinadas mudanças por eles desejadas no sentido de civilizar a cidade.

Seguiram sendo promovidas as provas de velocípedes em conjunto com corridas e saltos. A possibilidade de apostas animava os frequentadores, ainda que também fosse motivo de críticas (como as de Luiz Fernandes, que continuava a exaltar o caráter de educação física da modalidade ${ }^{23}$ ). Em março de 1884, se inaugurou um salão com um grande baile. As atividades musicais, que sempre marcaram as corridas dos dois clubes atléticos, cada vez mais se tornaram comuns no Olímpico, inclusive com a participação de importantes sociedades musicais de Niterói, como a Progresso de Icaraí, uma das mais renomadas da cidade.

$\mathrm{Na}$ programação dos eventos, passou-se a receber agremiações convidadas que apresentavam exibições de outras modalidades, como as de ginástica e esgrima do Real Clube Ginástico Português e do Congresso Ginástico Português. Houve até mesmo espetáculos circenses em meio aos páreos (como os do Circo Anglo Brasileiro, com seus exercícios acrobáticos).

O sucesso dessas iniciativas foi imediato. Os cronistas ressaltavam o grande público, a animação, a elegância dos trajes: "Foi uma verdadeira manhã de festa. Todos que ali foram saíram desejosos de voltar o mais breve possível, ávidos de saborear os numerosos divertimentos" (O FLUMINENSE, 1884a, p. 2). A sede do Clube Olímpico se tornou o "rendez vous elegante do high life niteroiense", nas palavras de um periodista da Corte (O PAIZ, 1886, p. 2).

Vejamos como Everardo Backheuser (1994) ${ }^{24}$ se referiu à agremiação que, quando criança, frequentou amiúde (sua residência era vizinha à sede), tendo, inclusive, disputado algumas provas. Para ele, "O Clube Olímpico [...] era, a seu tempo, o centro de mais alto relevo da sociedade niteroiense. Ali se reunia

\footnotetext{
23 Ver, por exemplo, O Fluminense (1884b).

24 A edição original dessa obra é de 1942. Everardo Backheuser foi um dos intelectuais niteroienses mais renomados. Apaixonado pela cidade, registrou nos jornais suas lembranças. No Rio de Janeiro, teve extensa e reconhecida atuação em vários âmbitos.
} 
o escol da Praia Grande para assistir e aplaudir os desportos da época” (p. 71). A seu ver, nos eventos celebrava-se que Niterói aderia e valorizava as diversões públicas, algo que caracterizava as cidades que buscavam progredir e se civilizar.

Constantemente, exaltou-se a presença e participação ativa das mulheres nas arquibancadas e nas raias ${ }^{25}$. Chegou a se estabelecer uma importante rivalidade entre Julieta do Couto (representando o Clube Atlético) e Magdaleine Laurente (representante do Olímpico). Houve pelo menos uma ocasião em que três páreos foram dedicados às corredoras (DIÁRIO DE NOTÍCIAS, 1885, p. 1).

Uma expressão de como se ampliaram os intuitos de contribuição da agremiação para com a "educação do físico" foi a oferta de aulas de ginástica, em outubro de 1884. Um cronista exaltou a iniciativa, sugerindo que:

Não há quem desconheça os proveitos destes exercícios, que, além de serem boa higiene, vigoram e robustecem o organismo, e na Europa, como entre nós e sobretudo nos Estados Unidos tem se colhido os mais excelentes resultados desse útil ensinamento (BRAZIL, 1884, p. 2).

Um cronista de $O$ Paiz (1884) também elogiou muito a iniciativa, tratada como um sinal de contribuição do Clube para a sociedade niteroiense. Mesmo com esses discursos, aqui se encontra um diferencial do Olímpico em relação ao Atlético. No primeiro, esse aspecto apareceu mais intensamente quando se comentavam as aulas de ginástica, sendo as corridas encaradas mais como espetáculo e divertimento. No segundo, as corridas em si eram tidas como preocupações com a saúde e higiene. Em ambos, era notável as exigências de vestimenta e comportamento. Era generalizada a ideia de que os eventos eram importantes para o progresso de Niterói. O que mudava era a ênfase na articulação assistir-praticar.

Assim como ocorreu com o Atlético, se argumentou que o Olímpico

25 Entre as competidoras se encontravam gente de famílias importantes da cidade, tais como Emiliana D'Oliveira, Isabel Borges, Joaquina da Silva, Elvira Muniz, Maria Surville, Thereza Sodré e Ubaldina Penaforte. 
influenciou a sociedade niteroiense. Para Backheuser, isso era inegável, perceptível, inclusive, no que tange ao crescimento da admiração por certos competidores:

O Clube Olímpico, malgrado minha falência de atleta-corredor, continuou a exercer sobre minha alma infantil uma impressão bem forte [...]. Não guardo a lembrança de todos os heróis daquela quadra de minha vida. Um porém, sobrenadou no tempo em que tudo consome, Erwin Voigt (BACKHEUSER, 1994, p. 73).

Para Backheuser, Erwin "era o nome laureado. Era aquele em que toda gente falava. $\mathrm{O}$ favorito. O invencível em todos os certames" (p. 73) ${ }^{26}$. Na verdade, os competidores eram as figuras principais num ambiente em que se respiravam ares juvenis e saudáveis. Os atletas começavam a entrar para o rol dos personagens sociais valorizados, exemplos de uma nova performance pública que crescentemente seria apreciada. Eram a melhor expressão da articulação das facetas propostas por Vigarello (2003): seu físico era a representação de um novo tempo, apontando para o suposto vigor de uma cidade que, modernizada, se consolidaria como ente autônomo e portadora de peculiaridades reconhecíveis, uma identidade bem delineada.

A despeito de seu sucesso, em 1887, se encerrou a trajetória do Clube Olímpico Guanabarense, provavelmente em decorrência de dissidências internas. Em agosto, as instalações foram leiloadas. De toda forma, a agremiação parece mesmo ter deixado marcas na trajetória da capital fluminense.

De fato, os nomes do Olímpico Guanabarense e da agremiação do Barreto seriam lembrados com saudade na segunda metade dos anos 1890 , quando o campo esportivo definitivamente se estruturaria em Niterói, momento no qual se destacariam novos clubes de corridas a pé e, notadamente, sociedades náuticas

\footnotetext{
${ }^{26}$ A família Voigt teve um longo envolvimento com o esporte em Niterói e no Rio de Janeiro, especialmente no atletismo e no remo. Participaram da criação de agremiações como o Veloclube de Icaraí e o Grupo de Regatas Gragoatá.
} 
que existem até os dias atuais (o Grupo de Regatas Gragoatá e o Clube de Regatas Icaraí). Nessas futuras experiências, ainda mais seria notável a articulação das três facetas da experiência corporal proposta por Vigarello (2003) (princípios da eficácia, propriedade e identidade). Isso, contudo, é tema para outro estudo.

\section{CONCLUSÃO}

No decorrer do século XIX, em Niterói circularam discursos de adesão ao ideário e imaginário da modernidade, compreensões relacionadas a noções de progresso e avanço civilizacional. No caso da antiga Vila Real da Praia Grande, essas representações também tinham em conta a legitimação de sua condição de capital, um intuito que se deparava com a força simbólica do Rio de Janeiro, situada do outro lado da Baía de Guanabara. Nesse processo, sentia-se a necessidade de educar a população para um novo perfil de cidade.

$\mathrm{Na}$ capital fluminense, essas ideias também foram relacionadas a experiências esportivas. São exemplos os discursos que se entabularam acerca das iniciativas dos clubes atléticos investigados. Antecedidas por algumas diversões nas quais se destacava a performance corporal (exibições e prática de ginástica e patinação, touradas, pioneiras regatas), trata-se de expressões da gestação de uma nova sensibilidade pública da qual fazia parte o desenvolvimento de um mercado de entretenimentos do qual faziam parte os esportes.

As iniciativas esportivas, espetáculos ao redor dos quais se forjaram discursos de educação física, eram encaradas como estratégias civilizatórias, possibilidade de educação corporal na medida em que informavam consideradas adequadas novas formas de se portar na cena pública, bem como certos cuidados com o corpo relacionados à saúde e higiene. Eram decorrências e agentes no que tange à construção de novas alternativas e restrições de exposição e usos do corpo, algo que envolvia homens e mulheres. Mais ainda, inferiu-se que poderiam contribuir com a consolidação de uma autonomia e identidade local. 
Trata-se de, uma vez mais dialogando com Vigarello (2003), processos de educação do físico (princípio da eficácia), de educação do espírito (princípio da propriedade) e de educação para a inserção em coletivos maiores (princípio da identidade). O que foi modificando-se no decorrer do tempo foi a ênfase em cada um desses princípios, ainda que, de alguma forma, sempre se manifestassem de maneira articulada nos discursos entabulados.

Não por acaso, as experiências dos clubes foram lideradas por gente ligada a uma burguesia urbana em formação. Eram mensageiras de uma ética e postura consideradas mais adequadas pelos que esperavam que a nação e a cidade pudessem progredir, deixando para trás um passado colonial que precisava ser abandonado.

Para tal, os cidadãos - elites e populares - precisavam ser educados. Os exercícios físicos - esporte e ginástica - eram representados como contributos para tal. Os clubes atléticos seriam uma prova concreta desse valor.

\section{REFERÊNCIAS}

A PÁTRIA, Niterói, 18 mai. 1856, p. 1.

ANAIS DA ASSEMBLEIA LEGISLATIVA PROVINCIAL DO RIO DE JANEIRO, 13 out. 1875 , p. 169.

AZEVEDO, Marlize Nazareth Soares de. Niterói urbano: a construção do espaço da cidade. In: MARTINS, Ismênia de Lima; KNAUSS, Paulo (org.). Cidade múltipla. Niterói: Prefeitura Municipal de Niterói, 1997. p. 19-71.

BACKHEUSER, Everardo. Minha terra e minha vida (Niterói há um século). Niterói: Niterói Livros, 1994.

BRAZIL, Rio de Janeiro, 10 out. 1884, p. 2.

CAMPOS, Maristela Chicharo de. O governo da cidade: elites locais e urbanização em Niterói (1835-1890). 2004. Tese (Doutorado em História) Universidade Federal Fluminense, Niterói/RJ, 2004. 
CARVALHO, José Murilo de. As conferências radicais do Rio de Janeiro: novo espaço de debate. In: CARVALHO, José Murilo de (org.). Nação e cidadania no Império: novos horizontes. Rio de Janeiro: Civilização Brasileira, 2007. p. 17-42.

CORREIO MERCANTIL, Rio de Janeiro, 14 jul. 1862a, p. 2.

CORREIO MERCANTIL, Rio de Janeiro, 18 jul. 1862b, p. 2.

CORREIO MERCANTIL, Rio de Janeiro, 18 jul. 1862c, p. 2.

DIÁRIO DE NOTÍCIAS, Rio de Janeiro, 2 jul. 1885, p. 1.

DIÁRIO DO RIO DE JANEIRO, 8 ago. 1840, p. 4.

DUNLOP, Charles Julius. Rio antigo. Rio de Janeiro: Editora Rio Antigo, 1960.

EDMUNDO, Luiz. O Rio de Janeiro do meu tempo. Rio de Janeiro: Conquista, 1956.

FERREIRA, Marieta de Moraes. Niterói poder: a cidade como centro político. In: MARTINS, Ismênia de Lima, KNAUSS, Paulo (org.). Cidade múltipla. Niterói: Prefeitura Municipal de Niterói, 1997. p. 73-100.

FORTE, José Mattoso Maia. Notas para a história de Niterói. Niterói: Instituto Niteroiense de Desenvolvimento Cultural/Prefeitura Municipal de Niterói, 1973.

FRIEDMAN, Michael T.; BUSTAD, Jacob T. Sport and urbanization. In: EDELMAN, Robert, WILSON, Wayne Wilson (org.). The Oxford handbook of sports history. Oxford: Oxford University Press, 2017. p. 145-158.

GAZETA DE NOTÍCIAS, Rio de Janeiro, 26 ago. 1877, p. 4.

HONORATO, Cezar; BEAUCLAIR, Geraldo. Niterói industrial: ramos da préindústria (1834-1860). In: MARTINS, Ismênia de Lima; KNAUSS, Paulo (org.). Cidade múltipla. Niterói: Prefeitura Municipal de Niterói, 1997. p. 101-130.

JORNAL DO COMÉRCIO, Rio de Janeiro, 24 out. 1837b, p. 3.

JORNAL DO COMÉRCIO, Rio de Janeiro, 31 dez. 1835, p. 3.

JORNAL DO COMÉRCIO, Rio de Janeiro, 4 jul. 1837a, p. 3.

JORNAL DO COMÉRCIO, Rio de Janeiro, 6 dez. 1837c, p. 2. 
JORNAL DO COMÉRCIO, Rio de Janeiro, 7 jul. 1862, p. 4.

LUCA, Tânia Regina de. História dos, nos e por meio dos periódicos. In: PINSKY, Carla Bassanezi (org.). Fontes históricas. São Paulo: Ed. Contexto, 2005. p. 111-153.

MARTINS, Carolina Machado. Água e memória. O sistema de abastecimento de água como patrimônio arquitetônico e urbanístico da cidade de Niterói (1819-1954). 2009. Dissertação (Mestrado em Arquitetura e Urbanismo) Universidade Federal Fluminense, Niterói/RJ, 2009.

MELO, Victor Andrade de (org.). Os sports e as cidades brasileiras: transição dos séculos XIX e XX. Rio de Janeiro: Apicuri/Faperj, 2010a.

MELO, Victor Andrade de. "Pois temos touros?": as touradas no Rio de Janeiro do século XIX (1840-1852). Análise Social, Lisboa, v. 50, n. 215, p. 382-404, 2015 .

MELO, Victor Andrade de. Antes do club: as primeiras experiências esportivas na capital do império (1825-1851). Projeto História, São Paulo, v. 49, p. 1-40, 2014.

MELO, Victor Andrade de. Entre a elite e o povo: o sport no Rio de Janeiro do século XIX (1851-1857). Tempo, Niterói, v. 21, n. 37, p. 208-229, 2015 b.

MELO, Victor Andrade de. Esporte e lazer: conceitos - uma introdução histórica. Rio de Janeiro: Apicuri/Faperj, 2010b.

MELO, Victor Andrade de. Mulheres em movimento: a presença feminina nos primórdios do esporte na cidade do Rio de Janeiro (século XIX-primeira década do século XX). Revista Brasileira de História, São Paulo, v. 27, n. 54, p. 127-152, 2007.

MELO, Victor Andrade de. O sport em transição: Rio de Janeiro, 1851-1866. Movimento, Porto Alegre, v. 21, n. 2, p. 363 - 376, 2015 c.

MELO, Victor Andrade de. Rio esportivo. Rio de Janeiro: Casa da Palavra, 2015d.

MELO, Victor Andrade de. Uma diversão civilizada - a patinação no Rio de Janeiro do século XIX (1872-1892). Locus, Juiz de Fora, v. 23, n. 1, p. 81-100, 2017.

MELO, Victor Andrade de; KARLS, Thaina Schwan. Novas dinâmicas de lazer: as fábricas de cerveja no Rio de Janeiro do século XIX (1856-1884). 
Movimento, Porto Alegre, v. 24, n. 1, p. 147-16o, jan./mar. 2018.

MELO, Victor Andrade de; PERES, Fabio de Faria. A gymnastica no tempo do Império. Rio de Janeiro: 7Letras/Faperj, 2014.

MELO, Victor Andrade de; PERES, Fabio de Faria. Primeiros ventos olímpicos em terras tupiniquins. Revista USP, São Paulo, n. 108, p. 39-48, 2016b.

MELO, Victor Andrade de; PERES, Fabio de Faria. Primórdios do esporte no Brasil - Rio de Janeiro. Manaus: Reggo Edições, 2016a.

MELO, Victor Andrade; SANTOS, Flávia da Cruz. Escola de Virtudes: a dança na São Paulo do século XIX (décadas de 1830-1860). Educação e Realidade, Porto Alegre, v. 43, n. 3, p. 1031-1054, set. 2018.

MENDONÇA, Alberto B. História do sport náutico no Brazil. Rio de Janeiro: s. n., 1909.

O FLUMINENSE, Niterói, 1 out. 1882b, p. 2.

O FLUMINENSE, Niterói, 11 out. 1882c, p. 2.

O FLUMINENSE, Niterói, 15 mai. 1881, p. 2.

O FLUMINENSE, Niterói, 16 jan. 1880, p. 4.

O FLUMINENSE, Niterói, 23 abr. 1884a, p. 2.

O FLUMINENSE, Niterói, 26 jul. 1885, p. 1.

O FLUMINENSE, Niterói, 27 nov. 1878, p. 3.

O FLUMINENSE, Niterói, 28 jul. 1882a, p. 1.

O FLUMINENSE, Niterói, 28 out, 1883a, p. 1.

O FLUMINENSE, Niterói, 29 jan. 1879a, p. 4.

O FLUMINENSE, Niterói, 5 set. 1884b, p. 3.

O FLUMINENSE, Niterói, 7 fev. 1879b, p. 4.

O FLUMINENSE, Niterói, 7 out. 1883b, p. 2.

O FLUMINENSE, Niterói, 7 out. 1883c, p. 2.

O GLOBO, Rio de Janeiro, 24 set. 1881, p. 2.

O PAIZ, Rio de Janeiro, 1 abr. 1886, p. 2. 
O PAIZ, Rio de Janeiro, 30 out. 1884, p. 1.

PEIXOTO, Gustavo Rocha. Niterói patrimônio: a melhor coisa para Niterói é a vista do Rio. In: MARTINS, Ismênia de Lima; KNAUSS, Paulo (org.). Cidade múltipla. Niterói: Prefeitura Municipal de Niterói, 1997. p. 217-228.

PIMENTA, Tânia Salgado; BARBOSA, Keith; KODAMA, Kaori. A província do Rio de Janeiro em tempos de epidemia. Dimensões, Vitória, v. 34, p. 145-183, 2015 .

RIBEIRO, José Alcides. Correio Mercantil do Rio de Janeiro: modos jornalísticos e literários de composição. In: CONGRESSO BRASILEIRO DE CIÊNCIAS DA COMUNICAÇÃO - INTERCOM, 18., 2005, Rio de Janeiro. Anais [...] Rio de Janeiro: Intercom; 2005.

SANT'ANNA, Denise Bernuzzi de. Descobrir o corpo: uma história sem fim. Educação e Realidade, Porto Alegre, v. 25, n. 2, p. 49-58, 2000.

SCHETINO, André. Pedalando na modernidade: a bicicleta e o ciclismo na transição dos séculos XIX e XX. Rio de Janeiro: Apicuri, 2008.

SOARES, Carmen Lúcia. Corpo, conhecimento e educação: notas esparsas. In: SOARES, Carmen Lúcia (org.). Corpo e história. Campinas: Autores Associados, 2001. p. 109-129.

SOARES, Emmanuel de Macedo. As ruas contam seus nomes. Niterói: Secretaria Municipal de Cultura, 1993.

VIGARELLO, Georges. A história e os modelos do corpo. Pro-Posições, Campinas, v. 14, n. 2 (41), p. 21-29, mai./ago. 2003.

VIGARELLO, Georges; HOLT, Richard. O corpo trabalhado: ginastas e esportistas no século XIX. In: CORBIN, Alain; COURTINE, Jean-Jacques; VIGARELLO, Georges (org.). História do corpo - volume 2. Rio de Janeiro: Vozes, 2008. p. 393-478. 
Nosso Cientista do Estado/Faperj. É coordenador do Sport: Laboratório de História do Esporte e do Lazer.

E-mail: victor.a.melo@uol.com.br

(1) http://orcid.org/0000-0002-1983-1475

Recebido em: 15 de agosto de 2018

Aprovado em: 05 de janeiro de 2019

(9)

Revista História da Educação - RHE

Associação Sul-Rio-Grandense de Pesquisadores em História da Educação - Asphe

Artigo de acesso aberto distribuído nos termos de licença Creative Commons. 